Special issue of the International Conference on Computational and Experimental Science and Engineering (ICCESEN 2014)

\title{
Structural Strength and Fatigue Life Calculation of Y32 Bogie Frame by Finite Element Method
}

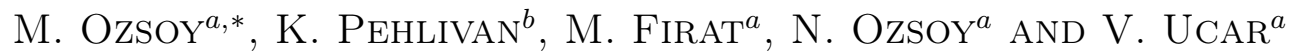 \\ ${ }^{a}$ Sakarya University Engineering Faculty Mechanical Engineering Department, Sakarya, Turkey \\ ${ }^{b}$ Sakarya University Institute of Naturel Science, Sakarya, Turkey
}

\begin{abstract}
In this study structural strength and fatigue life estimation of Y32 bogie frame were examined by finite element method. A static structural and fatigue life simulation were performed according to TS EN 13749 standard. The results of the static structural and fatigue life simulations depicted that Y32 bogie manufactured by Tuvasas achieved the regulations.
\end{abstract}

DOI: 10.12693/APhysPolA.128.B-327

PACS: 47.11.Fg, 46.50.+a

\section{Introduction}

Bogie is a chassis carrying wheels, suspension system, brakes and attached under the railway vehicles for running. Generally two pieces of bogies used for one passenger coach and a railway vehicle consists of several coaches. Bogies are critical components of a railway vehicle because of being running components. So during the design process there are a few standards must be obeyed for running at international railways. These standards can be detailed like methods of specifying structural requirements of bogie frames [1], wheelsets and bogies, wheelsets [2], draw gear and screw coupling [3], ride comfort for passengers, measurement and evaluation [4] etc.

Because of being an important piece of a railway vehicle, there are so many studies about bogies. M. Kassner [5], S. Shukla [6], Lu Yao-hui [7] studied about simulation of bogies structural strength, fatigue life and compared them with experimental results.

In this study a structural and fatigue analysis of Y32 bogie were examined according to TS EN 13749 standard. The static structural and fatigue life analysis were performed respectively. It was seen that Y32 bogie achieved the obligations specified at the TS EN 13749 standard.

\section{Geometrical and mathematical modeling}

Geometric model of the Y32 bogie was modelled as a solid model at PTC Creo Parametric 2.0 with some simplifications for finite element analysis, then transferred to the Ansys workbench environment. The material of the bogie frame was St $52-3$ (tensile strength $=500 \mathrm{MPa}$ and yield strength $=350 \mathrm{MPa}$ ). The mathematical model had 114831 elements. Loading conditions to the bogie frame are shown in Fig. 1a and revolute (rotating) joints for each axle bearing were considered as boundary conditions (Fig. 1b). Four springs $(k=1300 \mathrm{~N} / \mathrm{mm})$ were defined for each connection between the axle boxes and side frames.

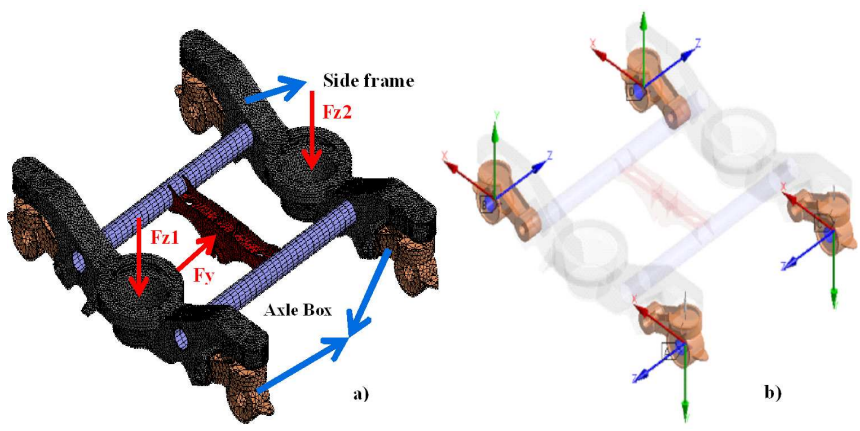

Fig. 1. (a) FEM mesh and loadings, (b) boundary conditions.

\section{Structural \& fatigue analysis}

The test consists of different phases, each of which corresponds to a load state that could be applied easily to the bogie frame. The loads are derived from normal service forces roll and bouncing which induce quasi-static and dynamic variations of vertical forces are represented by coefficients. The static test corresponding to vertical and transverse force combinations is defined by nine cases in Table I.

The fatigue test programme comprises three stages. The first consists of $6 \times 10^{6}$ cycles of application of the vertical and transverse forces, the second consists of $2 \times$ $10^{6}$ cycles of application of the vertical and transverse forces derived from those used for the first step, with the static parts remaining as before and the quasi-static and dynamic parts multiplied by 1.2 , the third is identical to the second, except that the coefficient of 1.2 is replaced by 1.4 .

\footnotetext{
*corresponding author; e-mail: ozsoy@sakarya.edu.tr
} 
TABLE I

Load cases for static tests [1].

\begin{tabular}{c|c|c|c}
\hline \hline \multicolumn{4}{c}{ Normal service loads } \\
\hline Load & \multicolumn{2}{|c}{ Vertical force per side frame } & \multirow{2}{*}{$F_{Y}[\mathrm{kN}]$} \\
\cline { 2 - 3 } CASE & $F_{Z 1}[\mathrm{kN}]$ & $F_{Z 2}[\mathrm{kN}]$ & \\
\hline 1 & 99.47 & 99.47 & 0 \\
2 & 89.53 & 69.63 & 0 \\
3 & 89.53 & 69.63 & 32.23 \\
4 & 129.32 & 109.42 & 0 \\
5 & 129.32 & 109.42 & 32.23 \\
6 & 69.63 & 89.53 & 0 \\
7 & 69.63 & 89.53 & -32.23 \\
8 & 109.42 & 129.32 & 0 \\
9 & 109.42 & 129.32 & -32.23
\end{tabular}

- No cracks are revealed at the end of the first two steps;

- During the third step very small cracks are permitted, if they appeared in service, would not necessitate immediate repair.

\section{Results}

\subsection{Structural analysis results}

Structural analysis were performed as nine cases. Vertical and lateral forces exerted on bogie were calculated towards the TS EN 13749. The results are collected in Table II.

TABLE II

Static structural analysis results.

\begin{tabular}{c|c|c|c|c|c|c|c|c|c}
\hline \hline & case 1 & case2 & case 3 & case 4 & case 5 & case 6 & case 7 & case 8 & case 9 \\
\hline $\begin{array}{c}\text { Maximum stress } \\
\text { (Von Misses) MPa }\end{array}$ & 194.44 & 161.5 & 165.47 & 236.68 & 240.65 & 161.3 & 165.27 & 236.39 & 240.35 \\
\hline $\begin{array}{c}\text { Minimum } \\
\text { safety factor }\end{array}$ & 1.8 & 2.17 & 2.12 & 1.48 & 1.45 & 2.17 & 2.12 & 1.48 & 1.46
\end{tabular}

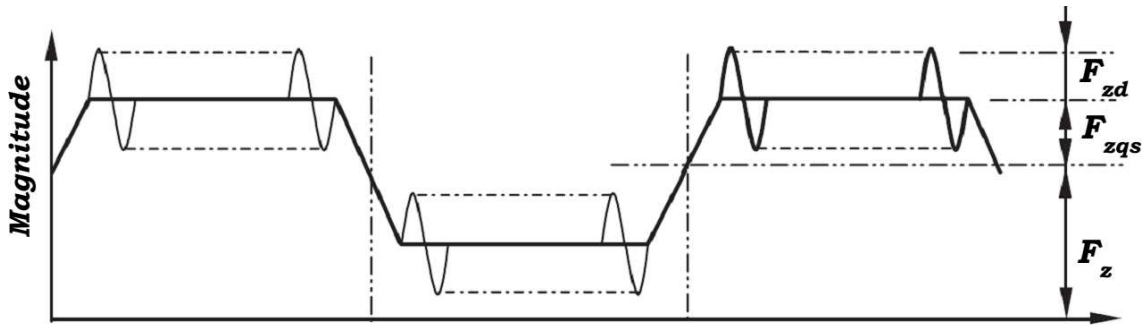

Fig. 2. Fatigue load-variation of vertical forces.

\subsection{Fatigue analysis results}

Figure 2 shows fatigue life calculated according the load variations given in Table III.

\section{Conclusion}

Results of the static structural analysis showed that after nine load cases the stresses occurred on the bogie frame were less than the material of bogie frames yield strength. At case nine which had the biggest loading amplitudes had a smallest structural safety factor as 1.46. According to fatigue analysis, bogie frame had a minimum safety factor of 1.4 and $2.5 \times 10^{7}$ cycle without any failure. Load and safety factor and life expectancy are shown in Figs. 3 and 4.

As a result, static structural and fatigue life analysis proved that Y32 bogie frame manufactured by Tuvasas fulfilled the requirements as specified TS EN 13749 standard.
TABLE III

Loads for fatigue test.

\begin{tabular}{c|c|c|c|c}
\hline \hline$F_{z}[\mathrm{kN}]$ & $F_{z q s}[\mathrm{kN}]$ & $F_{z d}[\mathrm{kN}]$ & $F_{y q s}[\mathrm{kN}]$ & $F_{y d}[\mathrm{kN}]$ \\
\hline 99.5 & 9.95 & 19.9 & 9.98 & 9.98
\end{tabular}

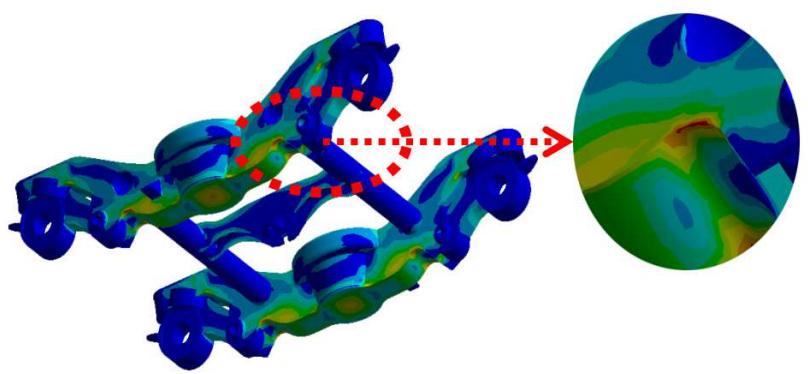

Fig. 3. The region of maximum stress occurred. 

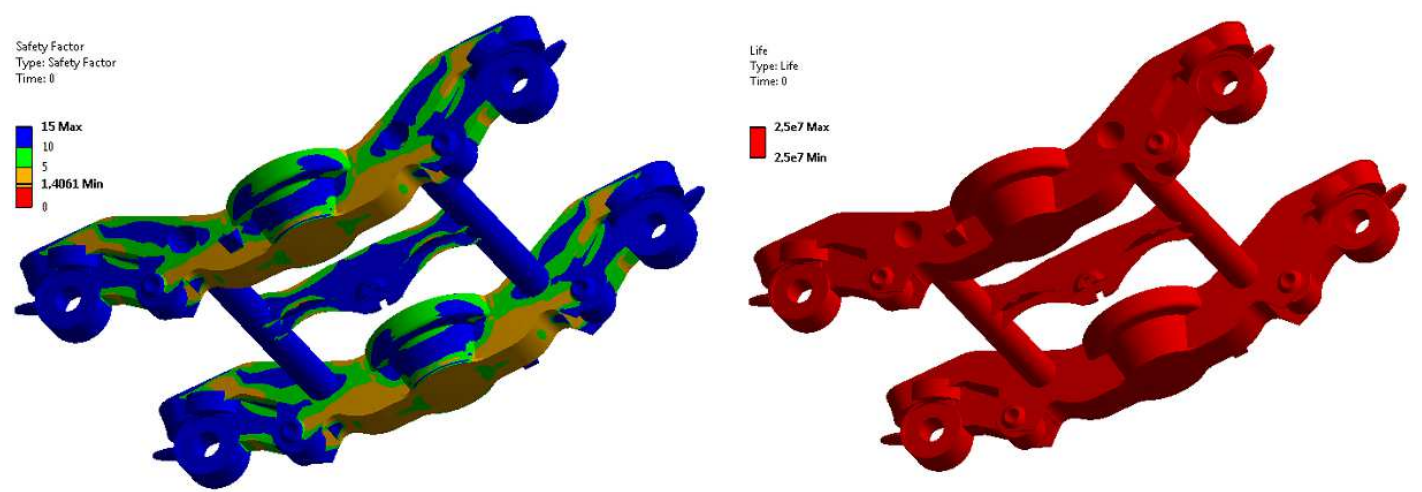

Fig. 4. (a) safety factor, (b) life expectancy.

\section{References}

[1] TS EN 13749, Railway applications, Wheelsets and bogies, Methods of specifying structural requirements of bogie frames, Turkish Standard, 2006.

[2] BS EN 13715, Railway applications, Wheelsets and bogies, Wheels, Tread profile, British Standard, 2010.

[3] BS EN 15566, Railway applications, Railway Rolling stock, Draw gear and screw coupling, British Standard, 2010.

[4] BS EN 12299, Railway applications. Ride comfort for passengers. Measurement and evaluation, British Standard, 2009.

[5] M. Kassner, Int. J. Fatigue 34, 103 (2012).

[6] S. Shukla, R. Gupta, N.S. Vyas, Int. J. Vehicle Struct. Syst. 2, 102 (2010).

[7] Lu Yao-hui, Int. Conf. System Science, Eng. Des. Manuf. Inform. 2010 1, 306 (2010). 